and profit, especially as the whole thread of the argument and salient points are conveniently recapitulated in the conclusion. Briefly, then, after setting the geological, climatic and vegetational scene and discussing the major subdivisions of the avifauna (forest and open country, montane and lowland), the book goes on to analyse its main features-endemism and affinities, qualitative differences according to geographical and environmental distribution, migrations within the continent and to and from the Palaearctic, ending with a review of the special and significant problems of the land-bird faunas of the islands round Africa.

Mr. Moreau himself suggests that his themes boil down to "the mutability of the whole biological scene" and "the problem of the nature of species comprising a bird fauna, whether of a continental area, of an island or of a vegetation community". These themes and their exposition are of very considerable value and interest to readers concerned with the conservation of Africa's fauna, and also to the great majority who can hope at most to have only brief and occasional glimpses of the wealth of Africa's bird life. Secondly, it becomes clear, in the light of the two themes, that observations of the most casual and infrequent visitor to the Continent, even his 'List' for any given area (provided always that it is accompanied by adequate and, preferably, quantitative data), can still make a significant contribution to filling the gaps and clarifying details-the need for which is constantly emphasised in this book.

Fifteen drawings by Robert Gillmor add embellishment and there are about the same number of well-chosen (but in two instances mis-captioned) photographs of habitat-types. Numerous maps are used to illustrate distributional points of every kind, and in some cases would have done so much more clearly if three instead of two colours had been used. However, the lay-out and production in general allows the book to be readily used as the treasure-house that it is.

HUGH ELLIOTT

\title{
A Field Guide to the Birds of New Zealand, by R. A. Falla, R. B. Sibson and E. G. Turbott. Collins, 36s.
}

Since the first pioneer effort, on the oceans, by W. B. Alexander, illustrated pocket field guides to bird identification, distribution and habits have spread first over North America and Europe and more recently to several other parts of the world. In some recent cases however ornithological knowledge is still too superficial and fragmentary to afford the depth and precision of the best models. Fortunately, New Zealand, with its compact area and avifauna and its fine team of resident ornithologists, forms an exception to this trend, and in depth and accuracy this latest Field Guide measures up to the highest standards.

Although the extinction, under Polynesian pressures, of over twenty forms of flightless moa was an ornithological catastrophe, followed in the nineteenth century by widespread destruction of native forests, uncontrolled shooting and indiscriminate introduction, outright extinctions have been fewer than is sometimes supposed, the unhappy exception this century being the huia. The authors, however, thoughtfully provide a full description of it, just in case even sixty years after its last known occurrence some lucky ornithologist may yet be able to emulate with it Dr. Orbell's rediscovery in 1948 of the takahe Notornis mantelli.

It is satisfactory to learn that "very few native species are now in serious danger of extinction, the elusive kakapo being perhaps an exception". Fortunately New Zealand is rich in offshore islands, a number of which have during the past seventy years become sanctuaries, and, although the battle for conservation continues there with no less noise and fury than anywhere else, any further setbacks will not be through lack of vigilance or resolution on the part of New Zealand conservationists, among whom the book's authors have played a valiant and effective role. 
With its excellent illustrations--18 plates, six in colour, by Chloe Talbot Kelly -and its wealth of information this book will be indispensable for ornithologists visiting New Zealand, and fascinating even to those who may never have the opportunity.

E. M. NICHOLSON

\section{Zoos of the World, by James Fisher. Aldus Books, 45s.}

The steady improvement of the zoological garden is one of the most interesting recent developments in the field of wildlife conservation, education and research. Traditionally zoos have been regarded as places of amusement and entertainment, but in the past decade the climate of opinion has changed considerably. Zoos are becoming increasingly aware of their educational responsibilities and their vital role in wildlife conservation by designing attractive, educational exhibits which will stimulate an interest in wild animals, collecting information on the wild animals in their care, and breeding rare animals.

Mr. Fisher shows how this change has come about. Based on his extensive knowledge of the history of zoos, experience of the numerous zoos he has visited, and statistics from the International Zoo Yearbook, he traces the development of the zoological garden from the menageries of the Ancient Egyptians in the third millennium BC, to the zoos of Rome and the Middle Ages, up to the present day. He examines the various aspects of the modern zoo, describing what is involved in the day-to-day running of a zoo, the breeding of animals in captivity, conservation activities, ways in which zoos obtain their animals, the trends in modern zoo design and construction, and the types of research being undertaken in the larger zoos today. His final chapter describes the tremendous progress zoos are making in improving their exhibits. The book is lavishly illustrated with blackand-white or colour photographs on every page.

As a guide to the ordinary member of the public, who would like to know what to look for when visiting a zoo, and to the conservationist or scientist who wants to know more about the educational or scientific role of the modern zoo, the book is invaluable. As Mr. Fisher says in his last chapter, he has tried to show that "zoos are part of man's deepest strivings to understand the world around him; that without them he would have learned much less than the little he knows about the animals he shares the world with; that with them he has found vast scope for research, scholarship, architectural imagination, conservation, preservation, tenderness, self-expression, and a lot of innocent fun."

CAROLINE MEDWAY

\section{Studying our Fellow Mammals, by Ernest P. Walker. Animal Welfare Institute, New York, $\$ 1.00$.}

The author has had long experience in the handling and care of mammals. As first commissioner of the Alaska Game Commission, head of the Federal Game and Bird Reservations, and finally assistant director of the Smithsonian Institution's National Zoological Park, he has acquired a wide knowledge of animal needs and methods of observing their behaviour. Not all zoologists would agree with some of the views expressed in this short, simply written book, but the 'Walker philosophy' is humane, informative and certainly stimulating. He has jotted down his thoughts, and they cover a vast field - conservation, behaviour, anatomy and physiology, care of captive animals, photography, classification and distribution-and he raises many thought-provoking subjects which should be of special interest to teachers for class discussion.

W. N. SCOTT 